\title{
Screening of the DNA mismatch repair genes MLH1, MSH2 and MSH6 in a Greek cohort of Lynch syndrome suspected families
}

\author{
Georgia Thodi ${ }^{1,2 \dagger}$, Florentia Fostira ${ }^{1 \dagger}$, Raphael Sandaltzopoulos ${ }^{2}$, George Nasioulas ${ }^{3}$, Anastasios Grivas ${ }^{4}$, \\ loannis Boukovinas ${ }^{5}$, Maria Mylonaki ${ }^{6}$, Christos Panopoulos ${ }^{7}$, Mirjana Brankovic Magic ${ }^{8}$, George Fountzilas ${ }^{9,10}$, \\ Drakoulis Yannoukakos ${ }^{1 *}$
}

\begin{abstract}
Background: Germline mutations in the DNA mismatch repair genes predispose to Lynch syndrome, thus conferring a high relative risk of colorectal and endometrial cancer. The MLH1, MSH2 and MSH6 mutational spectrum reported so far involves minor alterations scattered throughout their coding regions as well as large genomic rearrangements. Therefore, a combination of complete sequencing and a specialized technique for the detection of genomic rearrangements should be conducted during a proper DNA-testing procedure. Our main goal was to successfully identify Lynch syndrome families and determine the spectrum of MLH1, MSH2 and MSH6 mutations in Greek Lynch families in order to develop an efficient screening protocol for the Greek colorectal cancer patients' cohort.
\end{abstract}

Methods: Forty-two samples from twenty-four families, out of which twenty two of Greek, one of Cypriot and one of Serbian origin, were screened for the presence of germline mutations in the major mismatch repair genes through direct sequencing and MLPA. Families were selected upon Amsterdam criteria or revised Bethesda guidelines.

Results: Ten deleterious alterations were detected in twelve out of the twenty-four families subjected to genetic testing, thus our detection rate is $50 \%$. Four of the pathogenic point mutations, namely two nonsense, one missense and one splice site change, are novel, whereas the detected genomic deletion encompassing exon 6 of the MLH1 gene has been described repeatedly in the LOVD database. The average age of onset for the development of both colorectal and endometrial cancer among mutation positive families is 43.2 years.

Conclusion: The mutational spectrum of the MMR genes investigated as it has been shaped by our analysis is quite heterogeneous without any strong indication for the presence of a founder effect.

\section{Background}

Colorectal cancer (CRC) is the second most common cause of cancer-related deaths in the industrialized countries [1]. Approximately 5 to $10 \%$ of all colorectal cancer cases are due to highly penetrant alleles, which are inherited mostly in an autosomal dominant fashion [2].

\footnotetext{
*Correspondence: yannouka@rrp.demokritos.gr

+ Contributed equally

'Molecular Diagnostics Laboratory, I/R-RP, National Center for Scientific Research "Demokritos", Athens, Greece

Full list of author information is available at the end of the article
}

Lynch syndrome, also referred to as Hereditary Non Polyposis Colorectal Cancer (HNPCC), is the most common hereditary colon cancer syndrome [1]. However, its actual tumour spectrum is quite heterogeneous. Particularly, it confers high susceptibility to the development of cancer in the female reproductive tract [3], while the risk for developing cancer at other organs such as ovaries, stomach, small bowel, brain and urinary tract ranges from $2 \%$ to $13 \%$ [4]. It is attributed to germline mutations in either of the mismatch repair (MMR) genes: MLH1, MSH2, MSH6 and PMS2 [5]. The main function of the MMR gene products is to identify and correct
C Biomed Central 
mismatches as well as short insertion or deletion loops, which occur during replication and recombination [6]. In case of disabled MMR machinery, errors resulting to the contraction/expansion of tandemly repeated sequences, known as microsatellites, accumulate. This condition is termed as microsatellite instability (MSI). Detection of MSI has been a useful prescreening laboratory tool for the recognition of suspected Lynch syndrome cases $[2,7]$.

In clinical practice, the diagnosis of Lynch syndrome is mainly based on the Amsterdam criteria (AMS) [8]. However, families of small size or with atypical features, such as later age of onset for CRC, might be missed if only the AMS criteria are taken into consideration. Therefore, the Bethesda guidelines, which include all clinical conditions, have emerged as criteria of suspicion $[2,8]$.

The selection of the actual "high-risk" patients is a matter of significance, as a proper genetic testing should combine sequencing of the MMR gene coding regions with techniques for the detection of large genomic rearrangements. This is so, because no hotspots have been reported in the MMR genes while deletions/duplications account for a substantial part of mutations associated with Lynch syndrome [9-11]. Nevertheless, the presence of founder mutations have been well documented in some populations, thus facilitating the procedure of genetic testing [1].

The aim of this study was to successfully identify Lynch syndrome families and to report the $M L H 1$, MSH2 and MSH6 mutational spectrum within Greek colorectal cancer families. More specifically, the nature and frequency of the pathogenic alterations has been elucidated in order to develop an efficient DNA-based screening protocol for the Greek colorectal cancer patients' cohort.

\section{Methods}

\section{Patients}

The Amsterdam criteria and the revised Bethesda guidelines were used as selection criteria. Ultimately, twenty-four families were subjected for genetic testing, i.e. monitoring of point mutations or large genomic rearrangements in MLH1, MSH2 and MSH6 genes. Seventeen of the selected families fulfilled the Amsterdam criteria while seven families satisfied at least one of the revised Bethesda guidelines. All families were referred to Molecular Diagnostics Laboratory - NCSR "DEMOKRITOS". All patients gave us written informed consent for participation in our study. The study was approved by the Bioethics Committee of the National Centre for Scientific Research "Demokritos" (Reference Number 240/EH $\Delta / 10.8$ ) in agreement with the 1975 Helsinki statement, revised in 1983.

An additional 951 sporadic colorectal cancer cases, collected from Hellenic Community of Oncology
(HECOG), were screened for the genomic rearrangement identified, resulting in the deletion of exon 6 of MLH1 gene.

\section{DNA extraction}

Total genomic DNA was isolated from peripheral blood lymphocytes following the salt extraction procedure [12]. The quantity and quality of the DNA samples was determined with "NanoDrop" (Thermo Fisher Scientific, MA, USA).

\section{DNA sequencing}

All exons of the MLH1, MSH2 and MSH6 genes, including splice junctions, were amplified by polymerase chain reaction (PCR). The PCR products were purified with "Nucleofast 96 PCR Plates" (Macherey-Nagel, Germany) and then subjected to automated cycle sequencing with the Big Dye Terminator Cycle v3.1 sequencing kit (Applied Biosystems, Foster City, CA) and electrophoresis on an ABI Prism 310 Sequencer (PerkinElmer, Applied Biosystems, Foster City, CA). Primer pairs were designed with "Primer 3" software and are available upon request.

\section{RNA extraction and RT-PCR}

Total RNA was extracted from peripheral blood lymphocytes using Trizol (Invitrogen, Paisley, UK) following standard protocol. $1000 \mathrm{ng}$ of total RNA was reverse transcribed using $60 \mu \mathrm{M}$ of random hexamers and 10 units of MMLV reverse transcriptase (Roche Diagnostics, Mannheim, Germany) at $50^{\circ} \mathrm{C}$ for $30 \mathrm{~min}$, followed by enzyme inactivation at $85^{\circ} \mathrm{C}$ for $5 \mathrm{~min}$. Subsequently, cDNA was amplified on a new PCR reaction using the proper primer set.

\section{Multiplex Ligation-Dependent Probe Amplification (MLPA)} MLPA was performed with P003 kit (MRC-Holland, Netherlands) according to the manufacturer's instructions. Fragment analysis was conducted on ABI Prism 310 Genetic Analyzer using GeneMapper software (Applied Biosystems, Foster City, CA). 35 peaks corresponding to each exon of the $M L H 1$ and $M S H 2$ genes, as well as 7 peaks corresponding to DNA sequences outside these genes, were identified. Their migration was calculated according to the GeneScan ROX-500 size standard (Applied Biosystems, Foster City, CA). Decrease of 30 to $50 \%$ in the peak area(s) was considered as deletion of the corresponding exon(s), while increase of 30 to $50 \%$ as duplication of the corresponding exon(s).

\section{Long range polymerase chain reaction and breakpoint analysis}

$150 \mathrm{ng}$ of genomic DNA was amplified in a $50 \mu \mathrm{l}$ reaction volume using $1,5 \mathrm{mM} \mathrm{Mg}^{+2}, 300 \mu \mathrm{M}$ of each 
dNTP, 0.5 U of "Expand Long Range dNTPack" (Roche Diagnostics). Primers were designed between exon 5 and intron 7 of the $M L H 1$ gene. Cycling conditions were as follows: $94^{\circ} \mathrm{C}$ for $2 \mathrm{~min}, 94^{\circ} \mathrm{C}$ for $15 \mathrm{sec} / 62^{\circ} \mathrm{C}$ for $30 \mathrm{sec}\left\{-5^{\circ} \mathrm{C} /\right.$ cycle $\} / 68^{\circ} \mathrm{C}$ for $5 \mathrm{~min}\{\times 14$ cycles $\}, 94^{\circ} \mathrm{C}$ for $15 \mathrm{sec} / 55^{\circ} \mathrm{C}$ for $30 \mathrm{sec} / 68^{\circ} \mathrm{C}$ for $5 \min \{\times 20$ cycles $\}$, $68^{\circ} \mathrm{C}$ for $15 \mathrm{~min}$. The PCR product was further amplified using various primer pairs in a $20 \mu \mathrm{l}$ reaction. Cycling conditions were: $95^{\circ} \mathrm{C}$ for $2 \mathrm{~min}, 95^{\circ} \mathrm{C}$ for 25 sec $/ 59^{\circ} \mathrm{C}$ for $30 \mathrm{sec} / 72^{\circ} \mathrm{C}$ for $2 \min \{\times 25$ cycles $\}, 72^{\circ} \mathrm{C}$ for $5 \mathrm{~min}$. The PCR products were finally subjected to sequencing.

\section{PCR using diagnostic primers}

$100 \mathrm{ng}$ of genomic DNA was amplified in a $20 \mu \mathrm{l}$ reaction volume using $1.5 \mathrm{mM} \mathrm{Mg} \mathrm{Mg}^{+2}, 100 \mu \mathrm{M}$ of each dNTP, $1.25 \mathrm{U}$ of Taq polymerase (HyTest Ltd. Intelligate, Finland). Two primer sets were used (F3/R1 \& For $/ \operatorname{Rev} \times 15$ BRAF) in order to achieve the simultaneous amplification of the locus involving the exon 6 deletion and an independent locus used as an internal control $[13,14]$. Cycling conditions were as follows: $95^{\circ} \mathrm{C}$ for $3 \mathrm{~min}, 95^{\circ} \mathrm{C}$ for $30 \mathrm{sec} / 59^{\circ} \mathrm{C}$ for $30 \mathrm{sec} / 72^{\circ} \mathrm{C}$ for 45 sec $\{\times 35$ cycles $\}, 72^{\circ} \mathrm{C}$ for $7 \mathrm{~min}$.

\section{Results}

\section{Mutational analysis}

Twenty-four probands were screened for the presence of point mutations and large genomic rearrangements in either $M L H 1, M S H 2$ or MSH6 genes. Subsequently, when a pathogenic mutation was identified, family relatives were screened for the presence of the particular mutation. In total, forty-two samples were subjected to genetic testing. MLPA analysis was performed only in probands that tested negative for point alterations. Seventeen families fulfilled the Amsterdam criteria, while the remaining satisfied one or more of the revised Bethesda guidelines (age of onset $<50 \mathrm{y}, 1^{\text {st }}$ degree relatives diagnosed with CRC).

Twelve out of the twenty-four families found to carry pathogenic mutations in the mismatch repair genes (MLH1, MSH2 and MSH6) studied. Interestingly, all families that carry a pathogenic mutation fulfilled the Amsterdam criteria, whereas none of the families fulfilling at least one of the Bethesda guidelines carry deleterious aberration in the investigated genes.

A detailed family history along with the clinical data of each proband harboring a deleterious mutation is presented on table 1. The pathogenic mutations identified in twelve families are summarized on Table 2.

\section{Table 1 Features of families carrying a germline mutation in either of the MMR genes}

\begin{tabular}{|c|c|c|c|}
\hline $\begin{array}{l}\text { Patient } \\
\text { ID }\end{array}$ & $\begin{array}{l}\text { Clinical manifestations } \\
\text { (age of onset) }\end{array}$ & Family history & $\begin{array}{l}\text { Criteria used } \\
\text { for selection }\end{array}$ \\
\hline F33 & Endometrial Ca (40) & mother hysterectomy at $40 y-C R C$ at $70 y, 1^{\text {st }}$ brother $C R C$ at $50 y, 2^{\text {nd }}$ brother $C R C$ at $32 y$ & AMS $\|$ \\
\hline F39 & CRC (50) & $\begin{array}{l}\text { father stomach Ca at } 64 y \text {, sister ovarian Ca at } 56 y \text {, one } 2^{\text {nd }} \text { degree relative }(P) \text { brain Ca at } \\
47 y \text {, one } 2^{\text {nd }} \text { degree relative }(P) \text { pancreatic Ca at } 58 y, 22^{\text {nd }} \text { degree relatives }(P) C R C \text { at } 52 y \text { \& } \\
80 y \text { respectively }\end{array}$ & AMS $\|$ \\
\hline F41 & $\begin{array}{l}\text { Endometrial Ca ( 45)- } \\
\qquad \text { CRC (77) }\end{array}$ & $\begin{array}{c}1 \text { daughter endometrial Ca at } \mathbf{4 5 y}-\mathrm{CRC} \text { at } \mathbf{5 8 y}, 1 \text { grandson died from CRC at } 29 \mathrm{y}, \mathbf{1} \\
\text { granddaughter <5 polyps at } \mathbf{3 3 y} \text {, two brothers CRC }>50 y, 1 \text { sister endometrial Ca at } 26 y, 1 \\
\text { niece endometrial Ca at } 40 \mathrm{y}\end{array}$ & AMS $\|$ \\
\hline F74 & $\begin{array}{c}\text { CRC (42)- endometrial Ca } \\
(64)\end{array}$ & $\begin{array}{c}\text { mother endometrial Ca- CRC, brother CRC at } 26 y \text {, grandmother (M) CRC, uncle (M) CRC at } \\
37 y-C R C \text { at } 54 y \text {, cousin (M) CRC at } 40 y\end{array}$ & AMS $\|$ \\
\hline F84 & Endometrial Ca (40) & $\begin{array}{l}\text { mother died from pulmonary embolism, grandmother }(M) \text { stomach } C a \text { at } 60 y, 22^{\text {nd }} \text { degree } \\
\text { relatives } C R C, 12^{\text {nd }} \text { degree relative } C R C \text {-metachronous endometrial } C a\end{array}$ & AMS $\|$ \\
\hline F263 & $\begin{array}{l}\text { CRC (42)- } \\
\text { metachronous CRC (47) }\end{array}$ & $\begin{array}{l}\text { mother endometrial } \mathbf{C a} \text { at } \mathbf{5 0 y} \text {, grandfather }(M) \text { stomach } C a, 42^{\text {nd }} \text { degree relatives } C R C, 1 \\
2^{\text {nd }} \text { degree relative endometrial } C a \text { at } 34 y\end{array}$ & AMS $\|$ \\
\hline F111 & CRC (42) & father renal Ca-prostate Ca, grandfather (P) CRC, uncle (P) CRC & $\begin{array}{l}\text { Revised } \\
\text { Bethesda }\end{array}$ \\
\hline F150 & CRC (40) & father CRC at 48y, uncle (P) CRC at 50y & AMS I \\
\hline F656 & CRC (59) & $\begin{array}{c}\text { father CRC at } 41 y, 1^{\text {st }} \text { sister CRC at } 41 y, 2^{\text {nd }} \text { sister CRC at } 65 \mathbf{y} \text {, grandmother (P) } \\
\text { gynecological Ca at ?y }\end{array}$ & AMS $\|$ \\
\hline F1278 & CRC (33) & father CRC at 56y, grandmother (P) gynecological Ca at ?y- CRC at 43y & AMS $\|$ \\
\hline F68 & $\begin{array}{l}\text { CRC (28)- } \\
\text { metachronous CRC (44) }\end{array}$ & $\begin{array}{l}\text { father prostate } C a \text {, brother } \mathbf{4} \text { polyps at } \mathbf{3 6 y}, 12^{\text {nd }} \text { degree relative } C R C \text { at } 45 y \text {-metachronous } \\
\qquad C R C \text { at } 80 y, \mathbf{1} \mathbf{2}^{\text {nd }} \text { degree relative duodenum adenoCa at } \mathbf{4 2 y}\end{array}$ & $\begin{array}{l}\text { Revised } \\
\text { Bethesda }\end{array}$ \\
\hline F1376 & Ca cecum (30) & $\begin{array}{c}\text { mother CRC at 50y-polyp in the female reproductive tract at } \sim 45 y \text {, grandfather }(M) C R C \text { at } \\
\sim 80 y, 52^{\text {nd }} \text { degree relatives CRC }<60 y, 12^{\text {nd }} \text { degree relative endometrial } C a \text { at } \sim 50 y- \\
\text { metachronous } C R C \text { at } 65 y\end{array}$ & AMSII \\
\hline $\begin{array}{l}\text { 1SRB } \\
\text { (Serbian } \\
\text { origin) }\end{array}$ & CRC (49) & $\begin{array}{c}\text { father CRC at } 60 y, 2 \text { brothers } C R C \text { at } 49 \& 59 y \text { respectively, } 1 \text { sister endometrial } C a \text { at } 48 y- \\
\text { metachronous CRC at } 57 y, 1 \text { sister pancreatic Ca at } 63 y, 1 \text { niece CRC-synchronous stomach } \\
\text { Ca at } 25 y, 22^{\text {nd }} \text { degree relatives (P) CRC at } 50 \& 60 y \text { respectively, } 12^{\text {nd }} \text { degree relative (P) } \\
\text { bladder Ca at } 60 y\end{array}$ & AMSII \\
\hline
\end{tabular}

*Family members written in bold italic carry the particular mutation running in the family **(P): Paternal, (M): Maternal, CRC: ColoRectal Cancer, Ca: Cancer. 
Table 2 Germline mutations detected in either of the MMR genes.

\begin{tabular}{|c|c|c|c|c|c|}
\hline $\begin{array}{l}\text { Family } \\
\text { ID }\end{array}$ & Gene & Location & Nucleotide change & Protein effect & Method used \\
\hline F1376 & MLH1 & Exon 1 & c. $116+5 G>C$ & c.116_117ins227nt & Sequencing \\
\hline F656 & MLHI & Exon 1 & C. $116+5 G>C$ & c.116_117ins227nt & Sequencing \\
\hline F263 & MLH1 & Exon 6 & deletion of exon 6 & p.Glu153[33]fsX8 & MLPA/long range $P C R$ \\
\hline F33 & MLH1 & Intron 9 & c. $790+1 G>A$ & skipping of exons 9 and 10 & Sequencing \\
\hline F41 & MLHI & Intron 9 & c. $790+1 G>A$ & skipping of exons 9 and 10 & Sequencing \\
\hline F74 & MSH2 & Exon 5 & c. $940 \mathrm{C}>\mathrm{T}$ & p.GIn314X & Sequencing \\
\hline F84 & MSH2 & Exon 7 & c. $1237 \mathrm{C}>\mathrm{T}$ & p.Gln413X & Sequencing \\
\hline F68 & MSH2 & Exon 7 & c. $1276 G>C$ & partial skipping of exon 8 & Sequencing \\
\hline F1278 & MSH2 & Exon 13 & c.2089T > C & p.Cys697Arg & Sequencing \\
\hline F39 & $\mathrm{MSH} 2$ & Exon 13 & c. $2131 \mathrm{C}>\mathrm{T}$ & p.Arg711X & Sequencing \\
\hline 1SRB & MSH2 & Exon 13 & c. $2132 \mathrm{G}>\mathrm{C}$ & p.Arg711Pro & Sequencing \\
\hline F150 & MSH6 & Exon 5 & c.3202 C > T & p.Arg1068X & Sequencing \\
\hline F111 & MSH2 & Exon 12 & possible duplication of exon 12 & $?$ & MLPA \\
\hline
\end{tabular}

Three of the pathogenic nucleotide substitutions located in exons 5, 7 and 13 of the $M S H 2$ gene resulted in a premature stop codon. The nonsense mutations $M S H 2$, p.Gln314X (exon 5) and p.Gln413X (exon 7) are novel, to the best of our knowledge. The $M S H 2$, p. Arg711X (exon 13) has been reported several times in the LOVD database, as well as in an older study conducted in Greek colorectal cancer patients [15].

Two splice site changes were detected in four separate families. RT-PCR analysis of the $M L H 1$, c.116+5G > C mutation, which is located in intron 1 , results in a 227 base pair insertion taking place between exons 1 and 2 (data not shown). The specific mutation has been reported twice in the literature, while both bioinformatic prediction tools and in vitro techniques (conversion/ cDNA analysis) demonstrated that it activates a cryptic splice site [16,17]. On the other hand, the $M L H 1$, c.790 $+1 \mathrm{G}>$ A mutation, which is located in intron 9, induces skipping of exons 9 and 10 [18]. This mutation was identified in two distinct families, one of Greek and one of Cypriot origin. Thirteen different cancer cases have been reported in the Cypriot family, all potentially related to Lynch syndrome. However, one of the proband's daughters, who developed breast cancer at the age of 42 years, does not carry the particular mutation. The detailed family pedigree is shown on figure 1 .

Moreover, direct sequencing of DNA from samples F1278 and 1SRB revealed the presence of two discrete missense changes located in exon 13 of the $M S H 2$ gene. Exons 7 to 13 of the $M S H 2$ gene span the highly conserved ABC-ATPase domain, thus amino acid substitutions in this domain may have a severe impact on the protein's function [19]. The MSH2, p.Cys759Arg is characterized as pathogenic in the "MMR Gene Unclassified Variants Database" http://www.mmrmissense.info/. The MSH2, p.Arg711Pro mutation, which was identified in a Serbian family, is reported for the first time and its pathogenicity was assessed through bioinformatics tools (Table 3). All the protein web tools used (SIFT, PolyPhen, MAPP-MMR [20]) conclude that it is a deleterious change. In addition, it may influence the splicing process through the abrogation/creation of enhancer/ silencer motifs as prediction algorithms for the presence of such sequences have demonstrated (Table 3).

The $M S H 2$, c. $1276 \mathrm{G}>\mathrm{C}$ involves a novel $\mathrm{G}$ to $\mathrm{C}$ transversion located at the last nucleotide of the exon 7 of the MSH2 gene. According to the in silico analysis performed, the wild type splice donor is abolished (Table 4). Furthermore, the majority of the algorithms used for the prediction of enhancer/silencer motifs by the Human Splice Finder (v.2.4) web tool http://www. umd.be/HSF/[21] indicate that the c.1276G > C induces the abrogation or creation of such binding sites.

The MSH6, c.3202 C > T mutation, located on exon 5 of the gene, has been identified in an individual diagnosed with colorectal cancer at the age of 40. The specific mutation, although has been previously reported, is of interest since it is the first MSH6 mutation reported in a Greek family.

\section{Detection of benign polymorphisms}

Eleven intronic variants, three missense and four synonymous changes have been identified in the $M L H 1$, MSH2 and MSH6 genes (Table 5). Two of the reported polymorphisms (MSH2, c.646-46delC and MSH6, c.3678 A > G) are novel. 


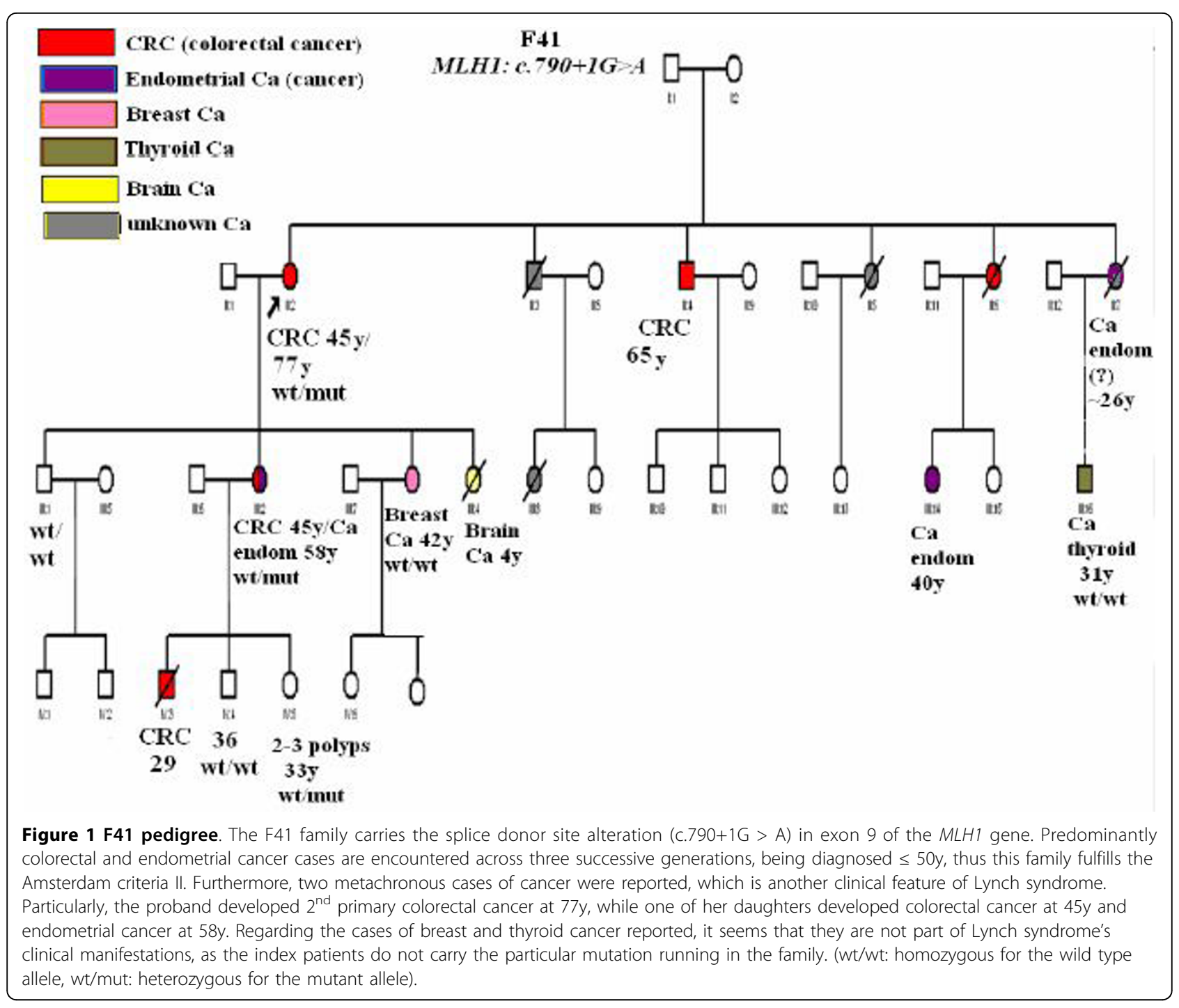

The MSH2, c.646-46delC, located in intron 3 of the gene, has not been previously described. As it was detected in one of our $M L H 1 / M S H 2$ mutation-negative patients, we tried to further characterize it through in silico analysis (Table 4). The Human Splice Finder (v.2.4) software demonstrated a significant variation in the branch site between the "wild type" and the "mutant" sequence, while both the NNSplice (0.9) http://www.fruitfly.org/seq_tools/splice.html and NetGene2 http://www.cbs.dtu.dk/services/NetGene2/ software packages presented no significant variation in either of the major splice sites. Subsequently, RNA sample was collected from the index patient in order to examine any possible alteration of the above variant on the RNA level. cDNA prepared was amplified with primers spanning exons 2 to 5 of the $M S H 2$ gene and revealed the presence of one discernible band corresponding to the wild type transcript (data not shown).
Therefore, it is obvious that the $M S H 2$, c.646-46delC is a non-pathogenic variation.

\section{Gene dosage alterations}

The eleven families tested negative for point mutations were screened for the presence of large genomic rearrangements using MLPA. The MLPA analysis indicated the presence of genomic rearrangements in two out of twelve families. Particularly, one deletion encompassing exon 6 of the MLH1 gene (c.454-?_545+?del) and one duplication involving exon 12 of the $M S H 2$ gene (c.1760-?_2005+?dup) have been demonstrated.

The $M L H 1$, c.454-?_545+?del was confirmed through an individual second MLPA experiment which involved the proband of the family (263), as well as one affected and one unaffected first-degree relative (Figure 2). Subsequently, a long range PCR was performed using a sense primer located in exon 5 and an antisense primer 
Table 3 In silico analysis of novel mutation MSH2, p.Arg711 Pro located in exon 13.

\begin{tabular}{|c|c|c|}
\hline $\begin{array}{l}\text { Methods of in silico } \\
\text { analysis }\end{array}$ & Result & Comments \\
\hline SIFT score & $0.00 \rightarrow$ pathogenic & $\begin{array}{l}\text { If SIFT score }<.05 \text { then the aa substitution is predicted to affect protein } \\
\text { function }\end{array}$ \\
\hline PolyPhen & Probably damaging (3.071) $\rightarrow$ pathogenic & $\begin{array}{l}\text { If PolyPhen score }>2 \text { then the aa substitution is predicted to affect } \\
\text { protein function }\end{array}$ \\
\hline MAPP-MMR & $40.700 \rightarrow$ pathogenic & $\begin{array}{l}\text { If MAPP-MMR score }>4.55 \text { then the aa substitution is predicted to affect } \\
\text { protein function }\end{array}$ \\
\hline NNSplice (0.9) & $\begin{array}{l}\text { SD: } 1.00 / 1.00 \text { No } \\
\text { SA: } 0.95 / 0.95 \text { Change }\end{array}$ & Scores predicted for the wt seq/score predicted for the mut seq \\
\hline NetGene2 Server & $\begin{array}{l}\text { SD: } 0.58 / 0.62 \text { No } \\
\text { SA: } 0.71 / 0.71 \text { Change }\end{array}$ & Scores predicted for the wt seq/score predicted for the mut seq \\
\hline \multirow{4}{*}{$\begin{array}{l}\text { Human Splice Finder v2.4 } \\
\text { (HSF) } \\
* * \\
\text { Rescue ESE } \\
\text { PESE octamers No } \\
\text { difference } \\
\text { ESS (Wang et al) } \\
\text { Fas-Ess hexamers } \\
\text { PESS octamers } \\
\text { IIEs (Zhang et al) } \\
\text { hnRP motifs }\end{array}$} & $\begin{array}{l}\text { SD: } 74.29 / 74.4 \\
\text { SA (c.2123):76.67/86.97 } \\
\text { SA (c.2126):75.87/79.36 } \\
\text { BP:81.68/86.61 }\end{array}$ & Scores predicted for the wt seq/score predicted for the mut seq \\
\hline & $\begin{array}{l}\text { ESE Finder:C.2129 SF2/ASF (IgM-BRCA1) } \rightarrow \\
\text { new site }\end{array}$ & \\
\hline & $\begin{array}{l}\text { EIEs (Zhang et al): } c .2127 \rightarrow \text { new site } \\
\text { ESE from HSF: c. } 21329 \mathrm{G} 8) \rightarrow \text { broken site } \\
\text { Silencer motifs (Sironi et al): c. } 2127 \rightarrow \text { new } \\
\text { site }\end{array}$ & \\
\hline & $\begin{array}{l}\text { Other splicing motifs (Goren et al): } \\
\text { c. } 2130 \rightarrow \text { new site }\end{array}$ & \\
\hline
\end{tabular}

*SD: splice donor, SA: splice acceptor, BP: branch point aa: aminoacid.

**These algorithms are included in the HSF analysis.

located in intron 7 , which preferentially amplified a smaller fragment of about $2.5 \mathrm{~kb}$, instead of the expected wild type fragment of 4937 bp (figure 3). The $2.5 \mathrm{~kb}$ fragment was subjected to sequencing in order to uncover the flanking regions of the deleted segment. Then, the $2.5 \mathrm{~kb}$ fragment was further amplified using various combinations of intronic primers. Sequencing of the smaller segments produced revealed the boundaries of the deletion, starting between nucleotides 157967158005 in intron 5 and ends between nucleotides 160376-160414 in intron 6 (GenBank Accession number AC011816). The breakpoints belong to AluSx_C repeats according to the results of RepeatMasker http://www. repeatmasker.org/cgi-bin/WEBRepeatMasker (Figure 3). The exact breakpoints could not be determined due to the presence of two identical $33 \mathrm{bp}$ sequences located within the AluSx_C elements which flank the deletion.

In order to assess the frequency of the MLH1, c.454-? _545+?del mutation in the Greek population, 951 unselected sporadic CRC cases were screened using diagnostic primers. The specific deletion was not detected among these samples, indicating that it is not a recurrent mutation in the context of the Greek population.
In the case of the duplication of exon 12 of the $\mathrm{MSH} 2$ gene identified by MLPA, the results have been confirmed by a second individual MLPA experiment, but it was not possible to be confirmed by another method.

\section{Discussion and Conclusions}

Lynch syndrome is a heterogeneous disorder in respects to its molecular basis, as well as its phenotypic expression. Therefore, the selection of the putative mutation carriers as well as the detection of the causative germline alterations is a challenging task. A variety of point mutations, such as substitutions, small insertions/deletions and splice site alterations, as well as large genomic rearrangements have been reported in the international InSiGHT (LOVD) database [10]. Particularly, genomic deletions account for approximately $10 \%$ of $M L H 1$ and MSH2 mutations, while genomic duplications have been observed in approximately $1 \%$ of the Lynch syndrome cases $[11,22]$. Furthermore, the fact that there are multiple susceptible genes that predispose to Lynch syndrome, immunohistochemistry and/or MSI should be used, where possible, as a pre-screening method to successfully identify the high risk families. In our series of 
Table 4 In silico analysis of novel sequence variations.

\begin{tabular}{|c|c|c|c|c|}
\hline $\begin{array}{l}\text { Gene (exon/ } \\
\text { intron) }\end{array}$ & $\begin{array}{l}\text { Nucleotide } \\
\text { change }\end{array}$ & Method & Result & Comments \\
\hline \multirow[t]{9}{*}{ MSH2 (exon 7) } & c.1276G > A & $\begin{array}{l}\text { Human Splice Finder } \\
\text { (v.2.4) } \\
\text { (HSF) } \\
\left(^{*}\right) \\
\text { EIEs (Zhang et al) No } \\
\text { Rescue ESE change } \\
\text { PESE octamers/no } \\
\text { ESS (Wang et al) motif } \\
\text { PESS octamers found } \\
\text { IIEs (Zhang et al) } \\
\text { Other splicing motifs } \\
\text { (Goren et al) }\end{array}$ & "wt" donor site broken (84.7/73.68) & $\begin{array}{l}\text { Scores predicted for the wt seq/ } \\
\text { score predicted for the mut seq }\end{array}$ \\
\hline & & & ESE Finder: c.1274 (SRp55) $\rightarrow$ new site & \\
\hline & & & Rescue ESE: c.1271/c.1272 $\rightarrow$ site broken & \\
\hline & & & ESE from HSF: c.1273/c.1276 (9G8) $\rightarrow$ site broken & \\
\hline & & & $\begin{array}{l}\text { Silencer motifs (Sironi et al): c.1271/ } \\
\text { c.1272 } \rightarrow \text { site broken }\end{array}$ & \\
\hline & & & Fas-Ess hexamers: c.1275 $\rightarrow$ site broken & \\
\hline & & & $\begin{array}{l}\text { hnRNP motifs: c.1273/c.1274 (hnRNP A1) } \rightarrow \text { site } \\
\text { broken }\end{array}$ & \\
\hline & & NNSplice (0.9) & "wt" donor site broken (0.91/-) & $\begin{array}{l}\text { Scores predicted for the wt seq/ } \\
\text { score predicted for the mut seq }\end{array}$ \\
\hline & & NetGene2 Server & "wt" donor site broken (0.83/-) & $\begin{array}{l}\text { Scores predicted for the wt seq/ } \\
\text { score predicted for the mut seq }\end{array}$ \\
\hline \multirow[t]{5}{*}{ MSH2 (intron 3) } & c.646/46delC & $\begin{array}{l}\text { Human Splice Finder } \\
\text { (v.2.4) } \\
\text { (HSF) } \\
\left(^{*}\right) \\
\text { ESE Finder } \\
\text { Rescue ESE } \\
\text { PESE octamers } \\
\text { EIEs (Zhang et al) No } \\
\text { ESE from HSF change } \\
\text { Silencer motifs/no } \\
\text { (Sironi et al) motif } \\
\text { ESS (Wang et al) found } \\
\text { IIEs (Zhang et al) } \\
\text { hnRNP motifs }\end{array}$ & $\begin{array}{l}\text { Variation in one of the potential branch points } \\
\text { (c.646-48) (79.39/23.83) }\end{array}$ & $\begin{array}{l}\text { Scores predicted for the wt seq/ } \\
\text { score predicted for the mut seq }\end{array}$ \\
\hline & & $\begin{array}{l}\text { Other splicing motifs } \\
\text { (Goren et al) }\end{array}$ & & \\
\hline & & & $\begin{array}{l}\text { PESS octamers: c.646-49 (46.39/87.56)/c.646- } \\
46 \rightarrow \text { new site }\end{array}$ & \\
\hline & & NNSplice (0.9) & $\begin{array}{l}\text { SD: } 0.90 / 0.90 \text { No } \\
\text { SA: } 0.90 / 0.91 \text { change }\end{array}$ & $\begin{array}{l}\text { Scores predicted for the wt seq/ } \\
\text { score predicted for the mut seq }\end{array}$ \\
\hline & & NetGene2 Server & $\begin{array}{l}\text { SD: } 0.76 / 0.76 \text { No } \\
\text { SA: } 0.23 / 0.25 \text { change }\end{array}$ & $\begin{array}{l}\text { Scores predicted for the wt seq/ } \\
\text { score predicted for the mut seq }\end{array}$ \\
\hline
\end{tabular}

$\left.{ }^{*}\right)$ these algorithms are included in the HSF analysis.

experiments, tumor samples from the patients studied were not available and therefore, direct sequencing analysis of the MMR genes was performed.

Nine pathogenic point mutations and one genomic rearrangement have been detected in twelve out of seventeen $(70.5 \%) \mathrm{AMS}^{+}$families studied. A $29.5 \%$ of $\mathrm{AMS}^{+}$families that included at least two colorectal or other Lynch syndrome-associated cancer cases remained unresolved. Additionally, no deleterious mutations were detected in patients with young age of onset for CRC, i.e. $<40$ years, but with no family history. Our results coincide with observations of previous studies which have demonstrated that a proportion as high as $50 \%$ of $\mathrm{AMS}^{+}$families harbour no pathogenic mutations in either of the major MMR genes, namely $M L H 1$ and $M S H 2$ genes [9]. Nevertheless, the detection rate among $\mathrm{AMS}^{+}$families was much higher than in families selected upon Bethesda guidelines, indicating the already reported higher specificity of the modified Amsterdam criteria in clinical practice. 
Table 5 Polymorphisms in either of the major MMR genes

\begin{tabular}{|c|c|c|c|c|}
\hline Gene & Location & Nucleotide change & Protein effect & Families with the variant \\
\hline \multirow[t]{3}{*}{ MLH1 } & Intron 6 & c. $545+72 \mathrm{~T}>\mathrm{A}$ & N.A & 2 \\
\hline & Exon 8 & c. $655 \mathrm{~A}>\mathrm{G}$ & p.lle219Val & $12^{*}$ \\
\hline & Intron 14 & c. $1668-19 A>G$ & N.A & $6^{*}$ \\
\hline \multirow[t]{6}{*}{ MSH2 } & Intron 1 & c. $211+8 G>C$ & N.A & 2 \\
\hline & Intron 1 & c. $211+9 C>G$ & N.A & 4 \\
\hline & Intron 3 & c.646-46delC & N.A & 1 \\
\hline & Exon 6 & C.965G > A & p.Gly322Asp & 6 \\
\hline & Intron 10 & c. $1661+12 G>A$ & N.A & $14^{*}$ \\
\hline & Intron 12 & c.2006-6T > C & N.A & $9^{*}$ \\
\hline \multirow[t]{10}{*}{ MSH6 } & Intron 1 & c. $261-36$ A > G & N.A. & 2 \\
\hline & Exon 1 & c.116 G > A & p.Gly39Glu & 2 \\
\hline & Exon 1 & C. 186 C > A & p. Arg62Arg & $2^{*}$ \\
\hline & Exon 2 & c. $276 \mathrm{~A}>\mathrm{G}$ & p.Pro92Pro & $4^{*}$ \\
\hline & Exon 3 & C.540 T > C & p.Asp180Asp & $4^{*}$ \\
\hline & Intron 4 & c.3173-101 C > G & N.A. & 1 \\
\hline & Exon 5 & c. $3438+14$ A > T & N.A. & $8^{*}$ \\
\hline & Intron 7 & c.3646+29_3646+32delCTAT & N.A. & $3^{*}$ \\
\hline & Intron 8 & c. $3802-40$ C > G & N.A. & $8^{*}$ \\
\hline & Exon 8 & c.3678 A > G & p.Ala1226Ala & 1 \\
\hline
\end{tabular}

Since the particular study includes a relatively small sample size, which can be a limitation when trying to provide a complete mutational spectrum, all available information on Greek putative Lynch syndrome families have been combined [15]. Thirty-three families have been screened for the presence of germline mutations in the $M L H 1$ and $M S H 2$ genes, while thirteen of them have been screened for the presence of germline mutations in the MSH6 gene. Sixteen mutations have been detected in eighteen of these families (Figure 4). To the best of our knowledge, eight of the pathogenic mutations recorded have never been described before.

Genomic rearrangements in the $\mathrm{MLH} 1$ and $\mathrm{MSH} 2$ genes represent $6 \%$ of the mutations identified in Greece, a percentage that falls within the range reported previously [9,22-25]. More specifically, in a German patients' cohort genomic deletions account for $10.6 \%$ of colorectal cancer families, while in the Dutch population genomic aberrations are encountered in $6.5 \%$ of $\mathrm{AMS}^{+}$ families [23,24]. If only $\mathrm{AMS}^{+}$families are taken into account, this proportion rises up to $8.3 \%$, which is in accordance with the observation made by Martínez-Bouzas et al [26]. Nonsense mutations and splice site changes seem to prevail among point alterations identified in the Greek patients' cohort. A quite interesting finding of this study is the high rate of novel mutations, which is calculated to be $53.3 \%$, highlighting the distinct heterogeneous nature of the Greek mutational spectrum of the $M L H 1$ and $M S H 2$ genes.

Despite the aforementioned heterogeneity, two of the mutations described, the $M L H 1$, c.790+1G > A transition and the $M L H 1$, c.116+5G > C transversion were detected in two distinct families during this study. The $M L H 1$, c.790+1G > A has been reported several times in different populations and further analysis is required in order to investigate the possible founder effect of this mutation within the Greek or Cypriot population. The extensive clustering of cancer cases within members of family 41 is of particular interest, since thirteen family members spread across three successive generations were diagnosed with five different cancer types. Interestingly, two of the family members were diagnosed with breast and thyroid cancer, respectively. These two types of cancer are not typical phenotypic features of the Lynch syndrome. Both patients were genotyped and found not to harbour the particular pathogenic mutation, indicating that they were probably sporadic cancer cases. On the contrary, other reports have been able to identify breast cancer in MMR mutation carriers, enhancing the theory that breast cancer can be a rare phenotypic feature of Lynch syndrome [27-31].

On the other hand, the $M L H 1$, c. $116+5 \mathrm{G}>\mathrm{C}$ has been reported only once before [16]. There is a possibility that the two families (F656, F1376) harbouring the $M L H 1$, c. $116+5 \mathrm{G}>\mathrm{C}$ mutation may be related, but it was not feasible to track down all the family relatives, since most of them live abroad. Further investigations are required in order to elucidate whether the particular alteration has a founder effect within the Greek population.

The aforementioned data underscore the heterogeneity of the $M L H 1$ and $M S H 2$ mutational spectrum in the 


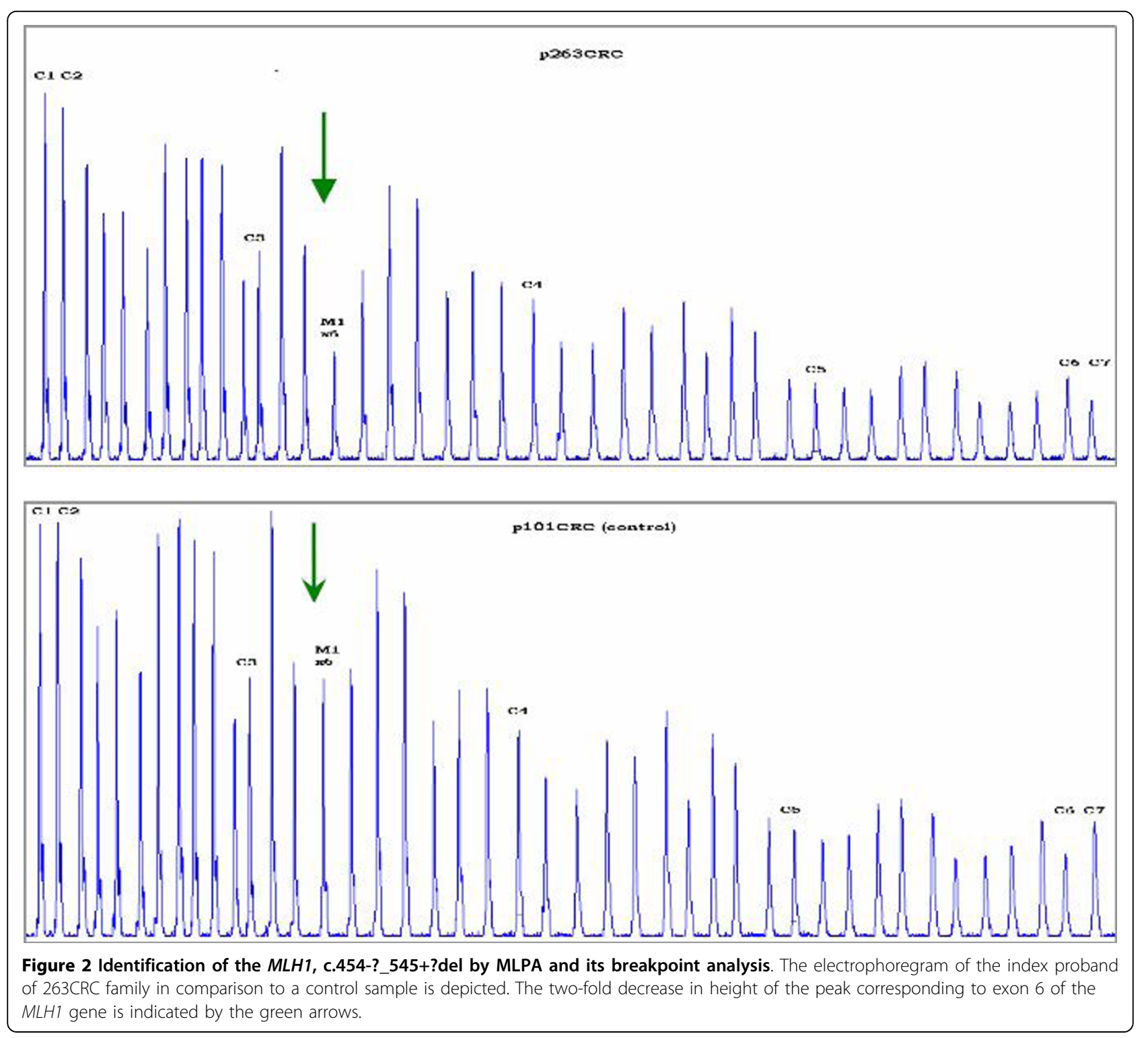

Greek population, since each Greek family harbours a distinct deleterious germline mutation, which can be of any type. Furthermore, the first germline pathogenic mutation in MSH6 gene in a Greek family is reported here. Therefore, a combination of techniques that will be able to detect both small size alterations within the three genes and large deletions/insertions is required for routine genetic testing of putative Lynch syndrome patients, which is in accordance with other studies.

Moreover, we have achieved to determine the breakpoints of the $M L H 1$, c.454-?_545+?del and subsequently to develop diagnostic primers for its rapid detection. This deletion was described initially by Viel and her colleagues [32] and has been reported several times since then. The possible founder effect of the specific mutation within the Greek population has been excluded when 951 unselected colorectal cancer cases were screened and no carriers of the specific mutation have been identified.

It is of great significance to obtain systematically data about the exact nature and frequency of the pathogenic mutations encountered in a particular patients' cohort, in order to customize the genetic testing to the population' s needs, which will eventually result in the reduction of the high cost of genetic testing along with the optimization of the detection rate.

Our results indicate the distinct, heterogeneous nature of Lynch syndrome's associated mutations in a Greek colorectal cancer patients' cohort, as well as the significant contribution of Amsterdam criteria in the 


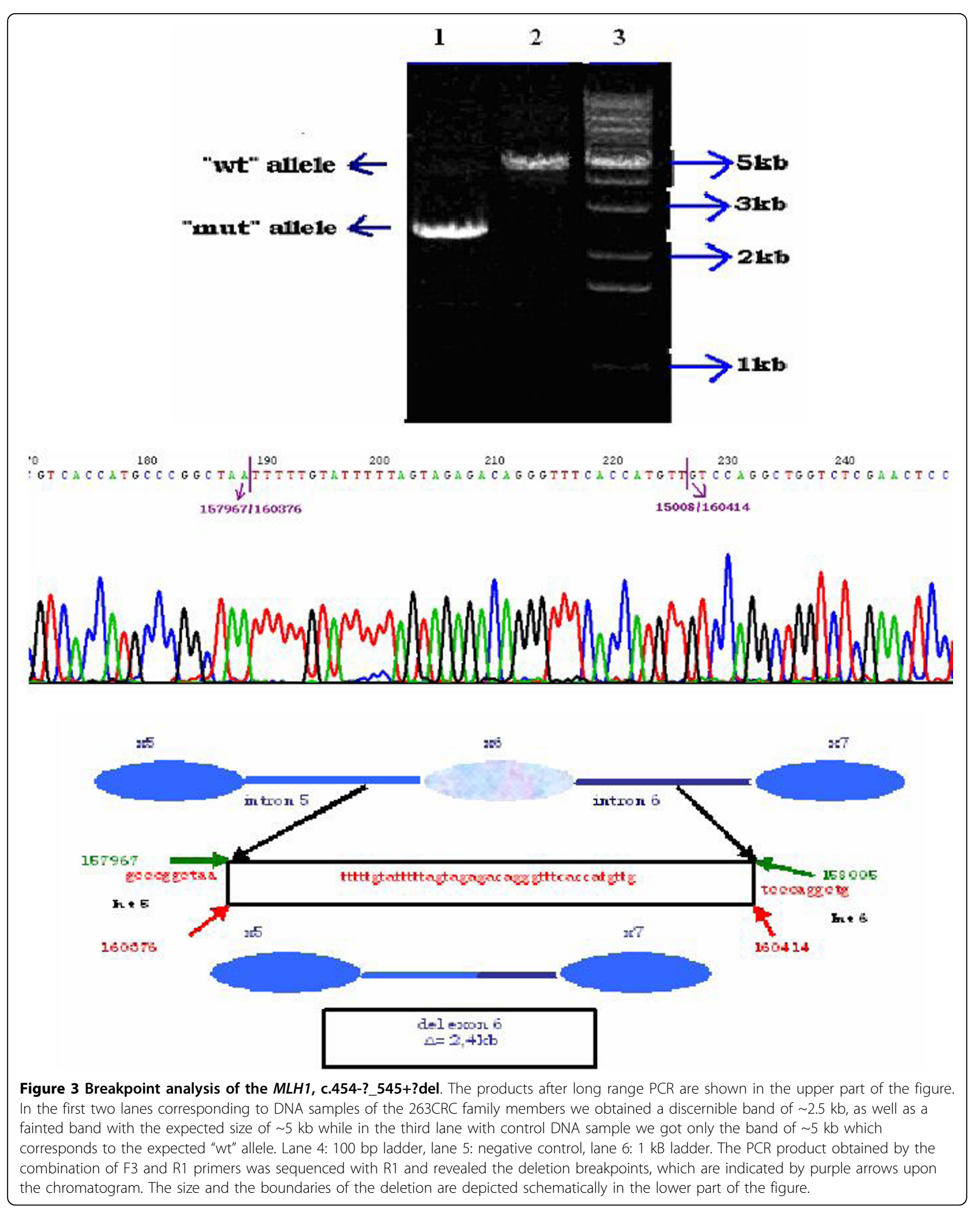



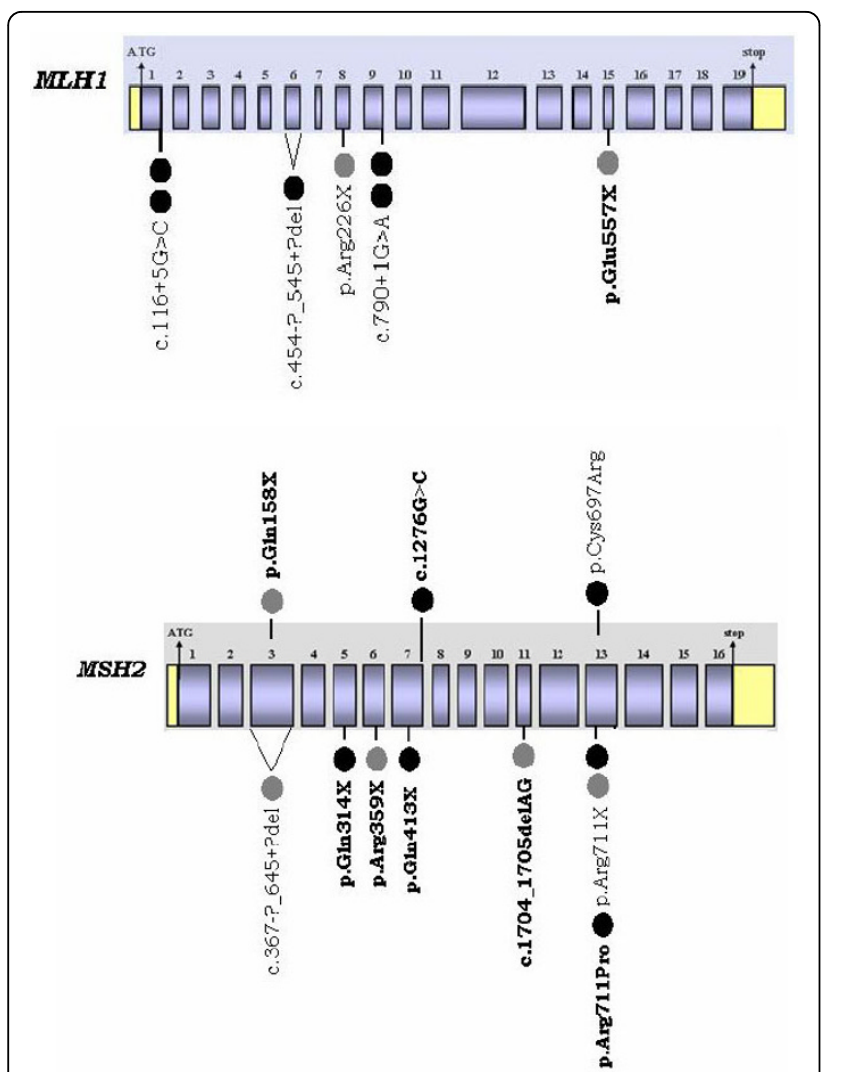

Figure $4 M L H 1$ and $M S H 2$ mutational spectrum in two Greek patients' cohorts. This configuration reviews all the pathogenic germline mutations detected in two Greek patients' cohorts. The black circles represent the families harboring deleterious mutations which were screened in the context of our study, while the grey ones the families carrying pathogenic alterations which were identified by Apessos et al [15]. The deleterious aberrations in bold have not been reported in other populations to the best of our knowledge.

identification of putative Lynch syndrome families. Consequently, the compilation of an accurate and detailed family history by the physician is a critical step for the diagnosis of Lynch syndrome.

\section{Abbreviations}

CRC: Colorectal cancer; HNPCC: Hereditary non polyposis colorectal cancer; MMR: Mismatch repair genes; MSI: Microsatellite instability; AMS: Amsterdam; MLPA: Multiplex ligation-dependent probe amplification; PCR: Polymerase chain reaction; InSiGHT: International society for gastrointestinal hereditary tumours.

\section{Acknowledgements}

This work is funded by $75 \%$ from the European Union - European Social Fund (E.S.F.) and by 25\% from the Greek Ministry of Development - General Secreteriat for Reraearch \& Technology (GSRT) and the private sector in the frame of Measure 8.3 of the Operational Programme - Competitiveness $-3^{\text {rd }}$ Framework program (PENED03E $\triangle 562)$.

\section{Author details}

${ }^{1}$ Molecular Diagnostics Laboratory, I/R-RP, National Center for Scientific Research "Demokritos", Athens, Greece. 'Laboratory of Gene Expression,
Molecular Diagnosis and Modern Therapeutics, Department of Molecular Biology and Genetics, Democritus University of Thrace, Alexandroupolis, Greece. ${ }^{3}$ Molecular Biology Research Center HYGEIA "Antonis Papayiannis", DTCA HYGEIA, Athens, Greece. ${ }^{4}$ Department of Medical Oncology - A, Metaxa Cancer Hospital, Piraeus, Greece. ${ }^{5}$ Theagenion Cancer Hospital of Thessaloniki, Thessaloniki, Greece. "Department of Gastroenterology, "Saint Panteleimon" General Hospital, Nikea, Greece. ${ }^{2}$ 2nd Medical Oncology Department, St. Savas Regional Oncology Hospital, Athens, Greece. ${ }^{8}$ Institute of Oncology \& Radiology of Serbia, Belgrade, Serbia. ${ }^{9}$ Department of Medical Oncology, Aristotle University of Thessaloniki, Papageorgiou Hospital, Thessaloniki, Greece. ${ }^{10}$ Hellenic Cooperative Oncology Group, Athens, Greece.

\section{Authors' contributions}

GT checked the family histories for their compliance with AMS clinical criteria for the diagnosis of Lynch syndrome, carried out the molecular genetic testing for $M L H 1$ and MSH2, i.e sequencing and MLPA, as well as the in silico and analysis and wrote the paper, FF checked the family histories, carried out a part of the sequencing for $\mathrm{MLH1}$ and $\mathrm{MSH}$ 2, carried out all the sequencing for MSH6 and revised the paper, RS designed the study and revised the paper, GN referred families to our laboratory after collecting a family history, AAG referred families to our laboratory after collecting a family history, IB referred families to our laboratory after collecting a family history, MM referred families to our laboratory after collecting a family history, CP referred families to our laboratory after collecting a family history, MBM referred a putative Lynch syndrome family of Serbian origin to our laboratory for final diagnosis through genetic testing, GF referred families to our laboratory after collecting a family history as well as blood samples from sporadic colorectal cancer patients collected by HECOG, DY designed the study and revised the paper. All authors have read and approved the final manuscript.

\section{Competing interests}

The authors declare that they have no competing interests.

Received: 5 September 2009 Accepted: 11 October 2010 Published: 11 October 2010

\section{References}

1. de la Chapelle A: Genetic predisposition to colorectal cancer. Nat Rev Cancer 2004, 4(10):769-780.

2. Abdel-Rahman WM, Mecklin JP, Peltomaki P: The genetics of HNPCC: application to diagnosis and screening. Crit Rev Oncol Hematol 2006, 58(3):208-220.

3. Vasen HF, Moslein G, Alonso A, Bernstein I, Bertario L, Blanco I, Burn J, Capella G, Engel C, Frayling I, et al: Guidelines for the clinical management of Lynch syndrome (hereditary non-polyposis cancer). J Med Genet 2007, 44(6):353-362.

4. Fostira F, Thodi G, Konstantopoulou I, Sandaltzopoulos R, Yannoukakos D: Hereditary cancer syndromes. J BUON 2007, 12(Suppl 1):S13-22.

5. Lynch HT, Lynch JF, Lynch PM, Attard T: Hereditary colorectal cancer syndromes: molecular genetics, genetic counseling, diagnosis and management. Fam Cancer 2008, 7(1):27-39.

6. Iyer RR, Pluciennik A, Burdett $V$, Modrich PL: DNA mismatch repair: functions and mechanisms. Chem Rev 2006, 106(2):302-323.

7. Peltomaki P: DNA mismatch repair and cancer. Mutat Res 2001, 488(1):77-85.

8. Vasen HF: Clinical description of the Lynch syndrome [hereditary nonpolyposis colorectal cancer (HNPCC)]. Fam Cancer 2005, 4(3):219-225.

9. Di Fiore F, Charbonnier F, Martin C, Frerot S, Olschwang S, Wang Q, Boisson C, Buisine MP, Nilbert M, Lindblom A, et al: Screening for genomic rearrangements of the MMR genes must be included in the routine diagnosis of HNPCC. J Med Genet 2004, 41(1):18-20.

10. Peltomaki $\mathrm{P}$, Vasen $\mathrm{H}$ : Mutations associated with HNPCC predisposition Update of ICG-HNPCC/INSiGHT mutation database. Dis Markers 2004, 20(4-5):269-276.

11. Baert-Desurmont S, Buisine MP, Bessenay E, Frerot S, Lovecchio T, Martin C, Olschwang S, Wang Q, Frebourg T: Partial duplications of the MSH2 and MLH1 genes in hereditary nonpolyposis colorectal cancer. Eur J Hum Genet 2007, 15(3):383-386. 
12. Miller $S A$, Dykes DD, Polesky HF: A simple salting out procedure for extracting DNA from human nucleated cells. Nucleic Acids Res 1988 16(3):1215.

13. Clendenning M, Baze ME, Sun S, Walsh K, Liyanarachchi S, Fix D, Schunemann V, Comeras I, Deacon M, Lynch JF, et al: Origins and prevalence of the American Founder Mutation of MSH2. Cancer Res 2008, 68(7):2145-2153.

14. Laud K, Kannengiesser C, Avril MF, Chompret A, Stoppa-Lyonnet D, Desjardins L, Eychene A, Demenais F, Lenoir GM, Bressac-de Paillerets B: BRAF as a melanoma susceptibility candidate gene? Cancer Res 2003, 63(12):3061-3065.

15. Apessos A, Mihalatos M, Danielidis I, Kallimanis G, Agnantis NJ, Triantafillidis JK, Fountzilas G, Kosmidis PA, Razis E, Georgoulias VA, et al: $\mathrm{hMSH} 2$ is the most commonly mutated MMR gene in a cohort of Greek HNPCC patients. Br J Cancer 2005, 92(2):396-404.

16. Casey G, Lindor NM, Papadopoulos N, Thibodeau SN, Moskow J, Steelman S, Buzin CH, Sommer SS, Collins CE, Butz M, et al: Conversion analysis for mutation detection in MLH1 and MSH2 in patients with colorectal cancer. JAMA 2005, 293(7):799-809.

17. Arnold S, Buchanan DD, Barker M, Jaskowski L, Walsh MD, Birney G, Woods MO, Hopper UL, Jenkins MA, Brown MA, et al: Classifying MLH1 and MSH2 variants using bioinformatic prediction, splicing assays, segregation, and tumor characteristics. Hum Mutat 2009, 30(5):757-770.

18. Hutter P, Couturier A, Membrez V, Joris F, Sappino AP, Chappuis PO: Excess of hMLH1 germline mutations in Swiss families with hereditary nonpolyposis colorectal cancer. Int J Cancer 1998, 78(6):680-684.

19. Warren JJ, Pohlhaus TJ, Changela A, lyer RR, Modrich PL, Beese LS: Structure of the human MutSalpha DNA lesion recognition complex. Mol Cell 2007, 26(4):579-592.

20. Chao EC, Velasquez JL, Witherspoon MS, Rozek LS, Peel D, Ng P, Gruber SB, Watson $P$, Rennert $G$, Anton-Culver $H$, et al: Accurate classification of $\mathrm{MLH} 1 / \mathrm{MSH} 2$ missense variants with multivariate analysis of protein polymorphisms-mismatch repair (MAPP-MMR). Hum Mutat 2008, 29(6):852-860.

21. Desmet FO, Hamroun D, Lalande M, Collod-Beroud G, Claustres M, Beroud C: Human Splicing Finder: an online bioinformatics tool to predict splicing signals. Nucleic Acids Res 2009, 37(9):e67.

22. Charbonnier F, Olschwang S, Wang Q, Boisson C, Martin C, Buisine MP, Puisieux A, Frebourg T: MSH2 in contrast to MLH1 and MSH6 is frequently inactivated by exonic and promoter rearrangements in hereditary nonpolyposis colorectal cancer. Cancer Res 2002, 62(3):848-853.

23. Wang $Y$, Friedl W, Lamberti C, Jungck M, Mathiak M, Pagenstecher $C$, Propping P, Mangold E: Hereditary nonpolyposis colorectal cancer: frequent occurrence of large genomic deletions in MSH2 and MLH1 genes. Int J Cancer 2003, 103(5):636-641.

24. Wijnen J, van der Klift $H$, Vasen $H$, Khan PM, Menko F, Tops $C$, Meijers Heijboer $H$, Lindhout D, Moller P, Fodde R: MSH2 genomic deletions are a frequent cause of HNPCC. Nat Genet 1998, 20(4):326-328.

25. Taylor CF, Charlton RS, Burn J, Sheridan E, Taylor GR: Genomic deletions in $\mathrm{MSH} 2$ or MLH1 are a frequent cause of hereditary non-polyposis colorectal cancer: identification of novel and recurrent deletions by MLPA. Hum Mutat 2003, 22(6):428-433.

26. Martinez-Bouzas C, Ojembarrena E, Beristain E, Errasti J, Viguera N, Tejada Minguez MI: High proportion of large genomic rearrangements in hMSH2 in hereditary nonpolyposis colorectal cancer (HNPCC) families of the Basque Country. Cancer Lett 2007, 255(2):295-299.

27. Westenend PJ, Schutte R, Hoogmans MM, Wagner A, Dinjens WN: Breast cancer in an MSH2 gene mutation carrier. Hum Pathol 2005, 36(12):1322-1326.

28. Geary J, Sasieni P, Houlston R, Izatt L, Eeles R, Payne SJ, Fisher S, Hodgson SV: Gene-related cancer spectrum in families with hereditary non-polyposis colorectal cancer (HNPCC). Fam Cancer 2008, 7(2):163-172.

29. Jensen UB, Sunde L, Timshel S, Halvarsson B, Nissen A, Bernstein I, Nilbert M: Mismatch repair defective breast cancer in the hereditary nonpolyposis colorectal cancer syndrome. Breast Cancer Res Treat 2010, 120(3):777-82.

30. Shanley S, Fung C, Milliken J, Leary J, Barnetson R, Schnitzler M, Kirk J: Breast cancer immunohistochemistry can be useful in triage of some HNPCC families. Fam Cancer 2009, 8(3):251-255.

31. Watson $P$, Vasen HF, Mecklin JP, Bernstein I, Aarnio M, Jarvinen HJ, Myrhoj T, Sunde L, Wijnen JT, Lynch HT: The risk of extra-colonic, extra- endometrial cancer in the Lynch syndrome. Int J Cancer 2008, 123(2):444-449.

32. Viel A, Petronzelli F, Della Puppa L, Lucci-Cordisco E, Fornasarig M, Pucciarelli S, Rovella V, Quaia M, Ponz de Leon M, Boiocchi M, et al: Different molecular mechanisms underlie genomic deletions in the MLH1 Gene. Hum Mutat 2002, 20(5):368-374.

33. Davies H, Bignell GR, Cox C, Stephens P, Edkins S, Clegg S, Teague J, Woffendin H, Garnett MJ, Bottomley W, et al: Mutations of the BRAF gene in human cancer. Nature 2002, 417(6892):949-954.

\section{Pre-publication history}

The pre-publication history for this paper can be accessed here: http://www.biomedcentral.com/1471-2407/10/544/prepub

doi:10.1186/1471-2407-10-544

Cite this article as: Thodi et al: Screening of the DNA mismatch repair genes MLH1, MSH2 and MSH6 in a Greek cohort of Lynch syndrome suspected families. BMC Cancer 2010 10:544.

\section{Submit your next manuscript to BioMed Central and take full advantage of:}

- Convenient online submission

- Thorough peer review

- No space constraints or color figure charges

- Immediate publication on acceptance

- Inclusion in PubMed, CAS, Scopus and Google Scholar

- Research which is freely available for redistribution

Submit your manuscript at www.biomedcentral.com/submit
C Biomed Central 